\title{
Separation of trace antimony and arsenic prior to hydride generation atomic absorption spectrometric determination
}

\author{
Müşerref Yersel, Aslı Erdem, Ahmet E. Eroğlu*, Talal Shahwan \\ Department of Chemistry, İzmir Institute of Technology, 35430 Urla-İzir, Turkey
}

Received 31 October 2004; received in revised form 31 December 2004; accepted 1 February 2005

Available online 3 March 2005

\begin{abstract}
A separation method utilizing a synthetic zeolite (mordenite) was developed in order to eliminate the gas phase interference of $\mathrm{Sb}$ (III) on As(III) during quartz furnace hydride generation atomic absorption spectrometric (HGAAS) determination. The efficiency of the proposed separation method in the reduction of suppression effects of transition metal ions on As(III) signal was also investigated. Among the volatile hydride-forming elements and their different oxidation states tested (Sb(III), Sb(V), Se(IV), $\mathrm{Se}(\mathrm{VI}), \mathrm{Te}(\mathrm{IV})$, and Te(VI)), only $\mathrm{Sb}$ (III) was found to have a signal depression effect even at low $\left(\mu \mathrm{g} 1^{-1}\right)$ concentrations under the experimental conditions employed. It has been shown that mordenite adsorbs $\mathrm{Sb}$ (III) quantitatively, even at a concentration of $1000 \mu \mathrm{g} \mathrm{l}^{-1}$, at $\mathrm{pHs}$ greater than two, and also, it reduces the initial concentrations of the transition metal ions to lower levels which can be tolerated in many studies. The adsorption of Sb(III) on mordenite follows the Freundlich isotherm and is endothermic in nature.
\end{abstract}

(C) 2005 Elsevier B.V. All rights reserved.

Keywords: Hydride generation atomic absorption spectrometry; Arsenic; Antimony; Interference; Mordenite

\section{Introduction}

Arsenic and antimony compounds are quite widespread in the environment. They have many industrial applications; they are used in semiconductors, in steel industry to reduce the ductility of the product and to increase brittleness, in semiconductors as an additive, in agriculture, and in glass manufacturing. Antimony is used in alloys and batteries. Also they have similar chemical and toxicological properties and they cause cancer in trivalent state [1].

Toxicity, reactivity and bioavailability of the elements depend on their chemical forms. This necessitates speciation analysis in which different chemical and physical forms of an analyte existing in a sample are determined. Speciation analysis mostly involves two steps, separation and determination; and one of the key issues of the speciation analysis is to preserve the composition of the sample during

\footnotetext{
* Corresponding author. Tel.: +90 232750 7533; fax: +90 2327507509.

E-mail address: ahmeteroglu@iyte.edu.tr (A.E. Eroğlu).
}

sampling, storage and pretreatment [2]. Sensitivity of the method should also be considered as the analytes of interest are usually at trace concentrations. Review articles on speciation of various elements can be found elsewhere [3].

There are many methods for the determination of antimony and arsenic in various matrices. Hydride generation atomic absorption spectrometry (HGAAS) is probably the most popular technique for the determination of arsenic and antimony, either directly or after a suitable pretreatment step. An important advantage of HGAAS is the separation of the analyte from the matrix. This facilitates reduction of spectral interferences and also preconcentration of the analyte. On the other hand, serious non-spectral interferences may arise in the liquid phase during hydride formation and transfer from solution (liquid phase interferences) or the interferents can influence the analyte in the gas phase (gas phase interferences) [4]. Liquid phase interferences are caused by changes in the rate of hydride release from the liquid phase or by a decreased efficiency of hydride release. Gas phase interfer- 
ences are apparently due to volatile species, most often by hydrides.

Many studies have been done in order to reduce the interferences in HGAAS, especially caused by transition metal ions and volatile hydride-forming elements. Welz and Schubert-Jacobs [5] studied the influence of acid and sodium borohydride concentrations to reduce the interference of transition metal ions in arsenic and selenium determination and concluded that higher acid-lower sodium borohydride concentrations improve the interference-free determination. Brindle and Le [6] used thiol containing compounds and amino acids for the enhancement of signals. Moreover, reducing agents such as L-cysteine [6,7], and thiourea [7] were also used for the reduction of transition metal ion interferences. Campos et al. [8] suggested picolinic acid and L-cysteine mixture to eliminate $\mathrm{Cu}$ and $\mathrm{Ni}$ interferences and tolerable concentrations were found up to 4000 and $1000 \mathrm{mg} \mathrm{l}^{-1}$ of nickel and copper, respectively.

Another important interfering group is volatile hydrideforming elements that have mutual interferences during determination [4]. Welz and Melcher [9] removed the effect of Se(IV) on As(III) and As(V) adding copper to the sample solution. The authors explained the mechanism in a way that, selenium hydride, which is formed first, reacts with copper ions in the solution to form insoluble selenides $(\mathrm{CuSe})$ whereas copper arsenide $\left(\mathrm{Cu}_{5} \mathrm{As}_{2}\right)$ is soluble in acids. Therefore, the evolution of selenium hydride from solution, and its interference on arsenic signal, is prevented. On the other hand, graphite tube atomizers at temperatures $>2000^{\circ} \mathrm{C}$ was suggested by Dittrich and Mandry [10]. The mechanism was explained as the formation of diatomic molecules between analyte and matrix elements such as AsSb. The effect of KI on the interferences by $\mathrm{Bi}, \mathrm{Se}$ and $\mathrm{Te}$ on $\mathrm{Sb}$ signal and the interferences of $\mathrm{Sb}, \mathrm{As}, \mathrm{Bi}, \mathrm{Te}$, and $\mathrm{Sn}$ on the Se signal using oxygen and a mixture of ozone were examined by Barth et al. [11]. In a study by Ay and Henden [12], a separation procedure using a GC column was applied to eliminate the inter-element interference of arsenic and antimony. In the GC column, arsine is eluted first and separated from stibine. They suggest taking stibine outside the atomizer for arsenic determination. In the next study by Erdem and Henden [13], a pyrex adsorption U-tube trap containing glass wool was placed between the drying tube and quartz tube atomizer and the mutual interference between As and Sb was investigated by selective heat decomposition of arsine and stibine.

As can be seen there are many studies on the reduction of HGAAS interferences during determination. In the present study, a different approach is proposed for the elimination/reduction of interferences on As signal prior to HGAAS determination. For the separation of $\mathrm{As}(\mathrm{III})$ and $\mathrm{Sb}$ (III) before hydride generation step a synthetic zeolite (mordenite) was used. It has also been shown that the proposed separation method has the ability to reduce the extent of transition metal interferences.

\section{Experimental}

\subsection{Reagents and materials}

All reagents were of analytical-reagent grade. Ultra-pure water $(18 \mathrm{M} \Omega)$ was used throughout the study. Glassware and plastic containers were cleaned by soaking in $10 \%(\mathrm{v} / \mathrm{v})$ nitric acid and rinsed with distilled water prior to use. The $\mathrm{As}(\mathrm{III})$ stock standard solution was prepared from $\mathrm{As}_{2} \mathrm{O}_{3}$ (Fischer) by dissolving in about $10 \%(\mathrm{v} / \mathrm{v}) \mathrm{H}_{2} \mathrm{SO}_{4}$. The solution was then neutralized with $0.1 \mathrm{M} \mathrm{NaOH}$ and was diluted to the required volume by ultra pure water (a similar dissolution procedure as explained in [9]). The $\mathrm{Sb}(\mathrm{III})$ stock standard solution from $\mathrm{C}_{4} \mathrm{H}_{4} \mathrm{KO}_{7} \mathrm{Sb}$ (Sigma) by dissolution in ultra pure water. Standards with lower concentrations were prepared daily from their stock standard solutions. Sodium borohydride solution $(1 \%, \mathrm{~m} / \mathrm{v})$ was prepared from fine granuled product (Merck) and was stabilized by the addition of $0.1 \%(\mathrm{~m} / \mathrm{v}) \mathrm{NaOH}$ (Merck). A synthetic zeolite, mordenite (Zeolyst International) was used in the sorption experiments. Mordenite used had a $\mathrm{SiO}_{2} / \mathrm{Al}_{2} \mathrm{O}_{3}$ mole ratio of $20, \mathrm{Na}_{2} \mathrm{O}$ of $0.08 \%(\mathrm{~m} / \mathrm{m})$, has a surface area of $500 \mathrm{~m}^{2} / \mathrm{g}$ and its nominal cation form was ammonium.

\subsection{Instrumentation and apparatus}

An atomic absorption spectrometer, Thermo Elemental Solar M6 Series with an air-acetylene burner was used in all the measurements. Antimony and arsenic determinations were performed by hydride generation atomic absorption spectrometry using their hollow cathode lamps at the wavelengths of 217.6 and $193.7 \mathrm{~nm}$, respectively. A deuterium hollow cathode lamp was used for background correction in all determinations. In HGAAS, the quartz tube atomizer was $10 \mathrm{~cm}$ long, $8 \mathrm{~mm}$ in internal diameter and $10 \mathrm{~mm}$ in external diameter with a $4 \mathrm{~mm}$ bore inlet tube fused at the middle for sample introduction. Air-acetylene flame was used for heating the quartz tube externally and nitrogen was used as the carrier gas. The hydride generation system coupled with segmented flow injection unit (FI 90) was used in all measurements for antimony and arsenic determinations. A schematic representation of the hydride generation apparatus used is shown in Fig. 1. It is a continuous hydride generation system segmented with air bubbles. Operating parameters for the HGAAS system are given in Table 1. In the determination of transition metal ions, flame atomic absorption spectrometry

Table 1

Operating parameters of the segmented flow injection (SFI-HGAAS) system used

\begin{tabular}{|c|c|}
\hline Carrier gas $\left(\mathrm{N}_{2}\right)$ flow rate $\left(\mathrm{ml} \mathrm{min}^{-1}\right)$ & 200 \\
\hline $\mathrm{HCl}$ concentration $(\mathrm{M})$ & 0.12 \\
\hline $\mathrm{HCl}$ flow rate $\left(\mathrm{ml} \mathrm{min}^{-1}\right)$ & 6.1 \\
\hline $\mathrm{NaBH}_{4}$ concentration & $\begin{array}{l}1 \%(\mathrm{~m} / \mathrm{v}) \text { stabilized with } \\
0.1 \%(\mathrm{~m} / \mathrm{v}) \mathrm{NaOH}\end{array}$ \\
\hline $\mathrm{NaBH}_{4}$ flow rate $\left(\mathrm{ml} \mathrm{min}^{-1}\right)$ & 3.0 \\
\hline
\end{tabular}




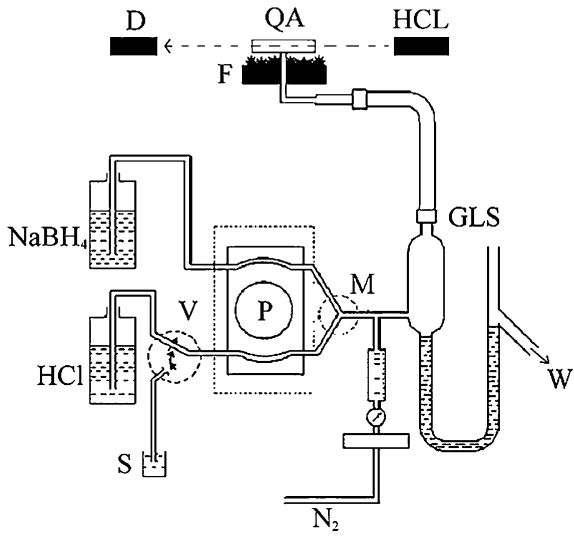

Fig. 1. Segmented flow injection (SFI-HGAAS) system used in this study (taken from Operator's Manual of the instrument). D: detector, QA: quartz tube atomizer, HCL: hollow cathode lamp, F: air-acetylene flame, S: acidified sample, V: injection value, $\mathrm{P}$ : two-channel peristaltic pump, M: mixing piece, GLS: gas/liquid separator, W: waste.

(FAAS) was applied. In batch sorption studies, Yellowline RS 10 (Staufen, Germany) reciprocating shaker was used to provide efficient mixing.

\subsection{Interference studies on As(III) signal in HGAAS measurements}

The interference effect of several transition metal ions on As(III) signal was investigated in such a way that various concentrations of the metals were prepared and spiked with As(III). The change in HGAAS signals of As(III) as a function of metal concentration was obtained. For this purpose, $30.0 \mathrm{ml}$ of separate transition metal ion solutions with the concentrations ranging from 0.1 to $5.0 \mathrm{mg} \mathrm{l}^{-1}$, were spiked with $25.0 \mu \mathrm{g} 1^{-1} \mathrm{As}(\mathrm{III})$. The solutions were analyzed with HGAAS system for As(III).

In a separate study, in order to investigate the interference effect of other volatile hydride-forming elements on As(III) signal, a similar strategy was followed with Se(IV), $\mathrm{Te}(\mathrm{IV})$, and $\mathrm{Sb}$ (III). As in the case of transition metal ions, $30.0 \mathrm{ml}$ of hydride-forming elements with concentrations $25.0-1000.0 \mu \mathrm{g} \mathrm{I}^{-1}$ were prepared separately and spiked with $25.0 \mu \mathrm{g} 1^{-1}$ As(III). The As signal from each solution was measured with HGAAS system.

\subsection{Sorption studies with mordenite}

Sorption characteristics of mordenite towards the selected transition metal ions and hydride-forming elements were investigated through batch process. The general strategy followed in the batch process was as follows: $30.0 \mathrm{ml}$ of the related solution was prepared and $0.3 \mathrm{~g}$ of mordenite was added into this solution. The mixture was shaken for 1-2 min manually and then placed on a reciprocating shaker for $15 \mathrm{~min}$. After the shaking period the mixture was centrifuged and the solid and solution phases were separated. The supernatant so- lution was analyzed by HGAAS for As(III) and $\mathrm{Sb}$ (III) and FAAS for the transition metals.

The effect of solution $\mathrm{pH}$ on the sorption of transition metal ions on mordenite was examined in the $\mathrm{pH}$ range $2.0-8.0$, for a transition metal concentration of $5.0 \mathrm{mg}^{-1}$. In the adjustment of $\mathrm{pH}, \mathrm{NH}_{3}(0.1-1.0 \mathrm{M})$ and $\mathrm{HCl}(0.1-1.0 \mathrm{M})$ were used. After the above-mentioned batch process, the concentrations of metal ions in the supernatant solutions were determined by FAAS and the percent sorption of transition metal ions on mordenite was calculated for each $\mathrm{pH}$.

The effect of initial concentrations of the transition metal ions on sorption on mordenite was investigated for the concentrations 1.0, 10.0, 100.0, and $1000.0 \mathrm{mg}^{-1}$. After the usual shaking and centrifugation steps, the supernatant solutions were analyzed to determine the concentrations of metals remaining in the solution. In addition, the supernatant solutions were spiked with $25.0 \mu \mathrm{g} 1^{-1}$ As(III) in order to see whether the remaining concentrations of the transition metal ions had any interference on As(III) signal.

Similar sorption experiments were performed with some other volatile hydride-forming elements; namely $\mathrm{Se}(\mathrm{IV})$, $\mathrm{Se}(\mathrm{VI}), \mathrm{Te}(\mathrm{IV}), \mathrm{Te}(\mathrm{VI}), \mathrm{Sb}(\mathrm{III})$, and $\mathrm{Sb}(\mathrm{V})$. The concentrations of all the species were $40.0 \mu \mathrm{gl}^{-1}$.

Based on the results of the interference study related with hydride-forming elements, a special attention was given to $\mathrm{Sb}$ (III) since it showed the most suppressive interference on As(III) signal. The effect of solution $\mathrm{pH}$ on the sorption of $\mathrm{Sb}$ (III) and $\mathrm{As}(\mathrm{III})$ was examined separately in the $\mathrm{pH}$ range $2.0-10.0$, and also in 1.0 and $4.0 \mathrm{M} \mathrm{HCl}$. The concentrations of both $\mathrm{Sb}$ (III) and As(III) were $40.0 \mu \mathrm{g}^{-1}$.

In addition to the $\mathrm{pH}$ experiments, the equilibrium sorption isotherm studies were conducted in order to better clarify the sorption of $\mathrm{Sb}$ on mordenite. These studies were also performed through batch process. The accurately weighed amounts of mordenite $(0.300$ or $1.000 \mathrm{~g})$ were added into $30.0 \mathrm{ml}$ of solutions containing the specified concentrations of $\mathrm{Sb}$ (III) (ranging from 5.0 to $500.0 \mathrm{mgl}^{-1}$ ) and the mixtures were shaken in a thermostated water bath $\left(30\right.$ or $\left.50^{\circ} \mathrm{C}\right)$ for an hour. At the end of the shaking period the solid and solution phases were separated through centrifugation and the concentrations of $\mathrm{Sb}$ in the supernatant solutions were determined by HGAAS or FAAS. The sorbed amount of $\mathrm{Sb}$ per unit mass of mordenite was calculated from the mass balance.

\section{Results and discussion}

\subsection{Interference studies}

\subsubsection{Effect of transition metal ions on As(III) signal}

As explained in Section 2.3, the change in As(III) signal as a function of transition metal ion concentrations ranging from 0.1 to $5.0 \mathrm{mg} \mathrm{l}^{-1}$ was investigated and the results are shown in Fig. 2. As can be seen from the figure, the highest signal depression was observed for $\mathrm{Ni}^{2+}$ and $\mathrm{Cu}^{2+}$ whereas the As(III) signal was not affected dramatically for 


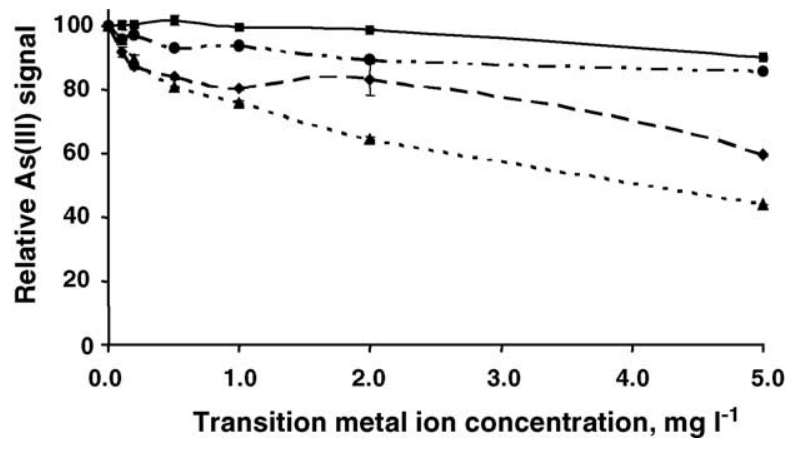

Fig. 2. Effect of transition metal ion concentration on $\mathrm{As}(\mathrm{III})$ signal: ( $\mathbf{\Delta})$ $\mathrm{Ni}^{2+} ;(\bullet) \mathrm{Ag}^{+} ;(\bullet) \mathrm{Cu}^{2+} ;(\mathbf{\square}) \mathrm{Pb}^{2+}$. (25.0 $\mu \mathrm{gl}^{-1} \mathrm{As}(\mathrm{III}), 1 \%(\mathrm{~m} / \mathrm{v}) \mathrm{NaBH}_{4}$, $0.12 \mathrm{M} \mathrm{HCl})$.

$\mathrm{Ag}^{+}$and $\mathrm{Pb}^{2+}$. These findings are in accordance with some studies in literature [14]. Higher concentrations $\left(>5.0 \mathrm{mg} \mathrm{l}^{-1}\right)$ were not tried because of the reduction of metal ions to elemental state with the injection of $\mathrm{NaBH}_{4}$ and thereby increasing the possibility of damaging and clogging of the pump tubings and narrow connection points of the SFIHGAAS.

\subsubsection{Effect of volatile hydride-forming elements on As(III) signal}

Volatile hydride-forming elements can cause serious gas phase interferences in HGAAS system. These interferences can take place either during the transfer of the hydride from the sample solution to the atomizer, or in the atomizer [4]. In order to test whether or not $\mathrm{Se}(\mathrm{IV}), \mathrm{Te}(\mathrm{IV})$ or $\mathrm{Sb}$ (III) had a suppression effect on As(III) signal, a $25.0 \mu \mathrm{gl}^{-1}$ As(III) standard in separate solutions of potential interferents; namely, 250.0 $\mathrm{g} \mathrm{I}^{-1} \mathrm{Sb}$ (III), Se(IV) and Te(IV), in different $\mathrm{HCl}$ concentrations $(0.12-3.0 \mathrm{M})$ was prepared. The relative As(III) signals are shown in Fig. 3(a). As can be seen from the figure, $\mathrm{Sb}$ (III) exhibited almost a constant signal suppression $(\sim 60 \%)$ at all $\mathrm{HCl}$ concentrations studied whereas no signal suppression was observed from $\mathrm{Se}(\mathrm{IV})$ or $\mathrm{Te}(\mathrm{IV})$ in $0.12 \mathrm{M}$ $\mathrm{HCl}$. But, immediately after this $\mathrm{HCl}$ concentration (e.g. in $0.24 \mathrm{M} \mathrm{HCl}$ ), a dramatic decrease in As(III) signal was obtained with $\mathrm{Se}(\mathrm{IV})$, almost $80 \%$ suppression, and about $20 \%$ decrease with Te(IV). These results can show the strong dependence of hydride generation reaction on sample acidity.

After this finding, effect of interferent concentration on As(III) signal was investigated in two different $\mathrm{HCl}$ concentrations. For this purpose, $25.0 \mu \mathrm{g} \mathrm{l}^{-1} \mathrm{As}$ (III) standard was prepared in varying concentrations $\left(25.0-1000 \mu \mathrm{g} \mathrm{l}^{-1}\right)$ of $\mathrm{Sb}(\mathrm{III}), \mathrm{Se}(\mathrm{IV})$ and $\mathrm{Te}(\mathrm{IV})$ in 0.12 and $1.2 \mathrm{M} \mathrm{HCl}$. The respective figures are shown in Fig. 3(b) and (c). As seen in Fig. 3(b), in 0.12 M HCl, Sb(III) suppressed the As(III) signal whereas no signal suppression was observed from Se(IV) and $\mathrm{Te}(\mathrm{IV})$. On the other hand, $1.2 \mathrm{M} \mathrm{HCl}$ created a more convenient environment for $\mathrm{Se}(\mathrm{IV})$ and $\mathrm{Te}(\mathrm{IV})$ to exhibit their interference effect on As(III) signal (Fig. 3(c)). Se(IV) was more effective and even no As(III) signal was obtained in presence of $500 \mu \mathrm{gl}^{-1} \mathrm{Se}(\mathrm{IV})$ in $1.2 \mathrm{M} \mathrm{HCl}$. In addition,
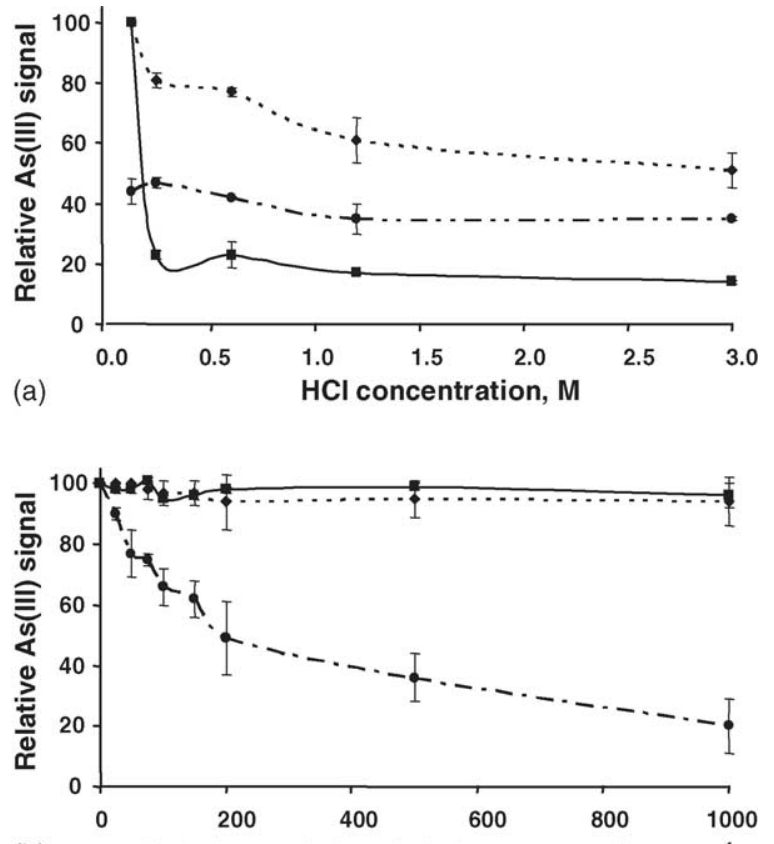

(b) $\quad \mathrm{Sb}$ (III) or $\mathrm{Te}(\mathrm{IV})$ or $\mathrm{Se}(\mathrm{IV})$ concentration, $\mu \mathrm{g} \mathrm{I}^{-1}$

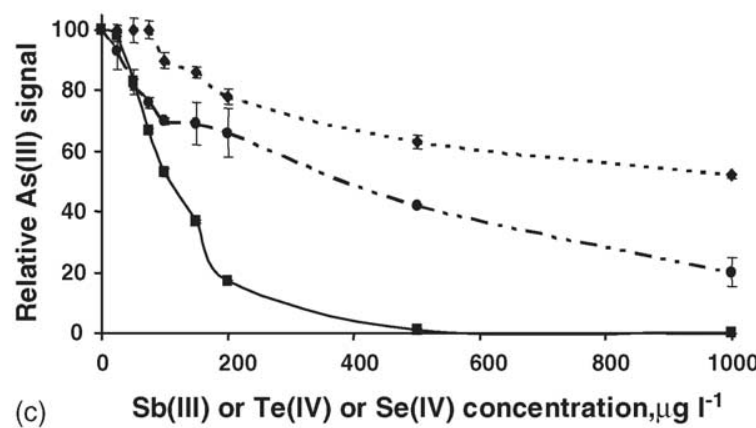

Fig. 3. (a) Suppression effect of $250.0 \mu \mathrm{g} 1^{-1}$ of (-) Sb(III), ( ) Te(IV) and (ם) $\mathrm{Se}(\mathrm{IV})$ on $\mathrm{As}(\mathrm{III})$ signal as a function of $\mathrm{HCl}$ concentration; (b) and (c) effect of the concentrations of the above-mentioned elements on As(III) signal in (b) $0.12 \mathrm{M} \mathrm{HCl}$ and (c) $0.24 \mathrm{M} \mathrm{HCl}\left(25.0 \mu \mathrm{g}{ }^{-1} \mathrm{As}(\mathrm{III}), 1 \%(\mathrm{~m} / \mathrm{v})\right.$ $\left.\mathrm{NaBH}_{4}\right)$.

the $\mathrm{pH}$ of the reaction mixture after mixing the sample (in different $\mathrm{HCl}$ concentrations) and the reducing agent $(1.0 \%$ $(\mathrm{m} / \mathrm{v}) \mathrm{NaBH}_{4}$ in $\left.0.1 \%(\mathrm{~m} / \mathrm{v}) \mathrm{NaOH}\right)$ was measured in the SFI-HGAAS system used. Initial concentrations of $\mathrm{HCl}$ and the $\mathrm{pH}$ of the mixtures were as follows; $0.012 \mathrm{M}(\mathrm{pH} 9.8)$, $0.060 \mathrm{M}$ (pH 9.0), 0.12 M (pH 6.6), 0.18 M (pH 1.4), 0.24 M ( $\mathrm{pH} 1.0), 0.60 \mathrm{M}(\mathrm{pH} \mathrm{0.5)}$, and $1.2 \mathrm{M}$ (pH 0.1). These results are in accordance with the results mentioned earlier by Belcher et al. [15]. According to the results, $\mathrm{H}_{2} \mathrm{Se}$ and $\mathrm{H}_{2} \mathrm{Te}$ could possibly not escape from the solution when the initial concentration of $\mathrm{HCl}$ is $0.12 \mathrm{M}$ (after mixing sample and reducing agent, $\mathrm{pH}$ of the solution was 6.6). On the other hand, when the initial $\mathrm{HCl}$ concentration was $0.24 \mathrm{M}, \mathrm{pH}$ of the solution changed to 1.0 after mixing, and therefore $\mathrm{H}_{2} \mathrm{Se}$ and $\mathrm{H}_{2}$ Te could escape from the solution and therefore cause gas phase interference. 
Table 2

Percent sorption of $\mathrm{Ag}^{+}, \mathrm{Ni}^{2+}, \mathrm{Cu}^{2+}$, and $\mathrm{Pb}^{2+}$ on mordenite and the effect of their remaining concentrations in effluents on $\mathrm{As}(\mathrm{III})$ signal (a) $\mathrm{Cu}^{2+}$, (b) $\mathrm{Ni}^{2+}$, (c) $\mathrm{Ag}^{+}$and (d) $\mathrm{Pb}^{2+}$

\begin{tabular}{|c|c|c|c|}
\hline Initial concentration $\left(\mathrm{mg} \mathrm{l}^{-1}\right)$ & Concentration in effluent $\left(\mathrm{mg} \mathrm{l}^{-1}\right)$ & $\%$ Sorption & $\%$ Suppression in As signal \\
\hline \multicolumn{4}{|l|}{ (a) $\mathrm{Cu}^{2+}$} \\
\hline 1 & $0.01 \pm 0$ & $99 \pm 0$ & $2 \pm 2$ \\
\hline 10 & $0.04 \pm 0$ & $100 \pm 0$ & $4 \pm 2$ \\
\hline 100 & $10 \pm 1$ & $90 \pm 1$ & $45 \pm 4$ \\
\hline 1000 & $778 \pm 33$ & $22 \pm 3$ & NA \\
\hline \multicolumn{4}{|l|}{ (b) $\mathrm{Ni}^{2+}$} \\
\hline 1 & ND & 100 & NS \\
\hline 10 & $0.03 \pm 0$ & $100 \pm 0$ & $1 \pm 1$ \\
\hline 100 & $19 \pm 0$ & $81 \pm 1$ & $96 \pm 1$ \\
\hline 1000 & $822 \pm 5$ & $18 \pm 1$ & NA \\
\hline \multicolumn{4}{|l|}{ (c) $\mathrm{Ag}^{+}$} \\
\hline 1 & $0.023 \pm 0$ & $98 \pm 1$ & NS \\
\hline 10 & $0.04 \pm 0$ & $99 \pm 0$ & NS \\
\hline 100 & $2 \pm 0$ & $98 \pm 0$ & $4 \pm 3$ \\
\hline 1000 & $362 \pm 7$ & $64 \pm 1$ & NA \\
\hline \multicolumn{4}{|l|}{ (d) $\mathrm{Pb}^{2+}$} \\
\hline 1 & ND & 100 & NS \\
\hline 10 & ND & 100 & NS \\
\hline 100 & $0.4 \pm 0$ & $100 \pm 0$ & NS \\
\hline 1000 & $301 \pm 12$ & $69 \pm 0$ & NA \\
\hline
\end{tabular}

NA: not analyzed; ND: not detected; NS: no suppression.

\subsection{Sorption studies}

\subsubsection{Sorption of transition metal ions}

Use of natural and synthetic zeolites including mordenite for the sorption of metal ions has been shown by many researchers [16-18]. In the present study, the initial experiment was planned to reveal the change in the percent sorption of the transition metal ions on mordenite versus the $\mathrm{pH}$ of the solution. It was found that any $\mathrm{pH}$ between 4.0 and 8.0 can be used for the quantitative sorption of all four transition metal ions. An interesting observation in this figure is that $\mathrm{Cu}^{2+}$ and $\mathrm{Ni}^{2+}$ showed a very similar behavior during sorption as seen in interference studies given in Fig. 2.

After determining the appropriate $\mathrm{pH}$ values, the specified amount of mordenite $(0.3 \mathrm{~g})$ was added into separate solutions of the four metal ions with different initial concentrations of $1.0,10.0,100.0$, and $1000.0 \mathrm{mg}^{-1}$. The concentrations of the metal ions that remained in the solution after sorption are given in Table 2. Also given in the table, the percent suppression of the As(III) signal when the supernatant solutions were spiked with $25.0 \mu \mathrm{g} \mathrm{l}^{-1} \mathrm{As}$ (III). As can clearly be seen from the table, when the initial concentration of the metals is $1000.0 \mathrm{mg} \mathrm{l}^{-1}$, mordenite cannot decrease their concentration to a tolerable level. The percent suppression effect of the remaining concentration of metal ions was not examined due to the possibility that such high concentrations could have caused some uncontrollable problems such as the formation of dispersed metals in the solution and the clogging of connection points in the SFI-HGAAS system. In the case of $\mathrm{Ag}^{+}$ and $\mathrm{Pb}^{2+}$, even an initial concentration of $100.0 \mathrm{mg} \mathrm{l}^{-1}$ did not cause any suppression since the percent sorption was still 98 and 100, respectively. The concentration of $\mathrm{Ag}^{+}$remained in the solution was $2.0 \mathrm{mg} \mathrm{l}^{-1}$ and this relatively low concen- tration caused only a $4 \pm 3 \%$ suppression in As(III) signal. This finding supports also the observations given in Fig. 2. The concentrations of $\mathrm{Cu}^{2+}$ and $\mathrm{Ni}^{2+}$ remained in the solution after $100.0 \mathrm{mg} \mathrm{l}^{-1}$ initial concentration of the metal ions were mixed with mordenite were $10 \pm 1$ and $19 \pm 1 \mathrm{mgl}^{-1}$, respectively. These concentrations of $\mathrm{Cu}^{2+}$ and $\mathrm{Ni}^{2+}$ were still very effective in suppression of As(III) signal. In both cases, the injection of $\mathrm{NaBH}_{4}$ caused the metal ions to be converted to elemental state and be dispersed in the solution, which possibly adsorbed $\mathrm{AsH}_{3}$ as soon as it was formed. With the initial concentrations of 1.0 and $10.0 \mathrm{mg} \mathrm{l}^{-1}$, mordenite decreased the concentrations of the metal ions below $0.04 \mathrm{mg} \mathrm{l}^{-1}$, and this and lower concentrations of the metals had a very slight suppression on As(III) signal only in the case of $\mathrm{Ni}^{2+}$. These results indicate clearly the potential of mordenite in reducing the interference effect of transition metal ions on As(III) signal.

\subsubsection{Sorption of volatile hydride-forming elements}

The sorption of different oxidation states of Se, Te, and Sb on mordenite was investigated as explained in Section 2.4. At the end of the usual sorption procedure, the lower oxidation states of the volatile hydride-forming elements; namely, $\mathrm{Sb}$ (III), Se(IV) and Te(IV) were determined by SFI-HGAAS directly after bringing it to the required acidity for hydride generation step. On the other hand, a prereduction step was applied to measure the higher oxidation states ( $\mathrm{Sb}(\mathrm{V}), \mathrm{Se}(\mathrm{VI})$ and $\mathrm{Te}(\mathrm{VI}))$. Treatment of the supernatant solution with $2 \%$ $(\mathrm{m} / \mathrm{v}) \mathrm{L}$-cysteine was sufficient for $\mathrm{Sb}(\mathrm{V})$ to $\mathrm{Sb}(\mathrm{III})$ reduction [19] whereas heating the solution in $6 \mathrm{M} \mathrm{HCl}$ served as an efficient prereduction step for $\mathrm{Se}(\mathrm{VI})$ [20] and $\mathrm{Te}(\mathrm{VI})$ [21].

Among the elements and their oxidation states examined, mordenite showed selectivity only to $\mathrm{Sb}$ (III) $(95 \pm 2 \%)$ 


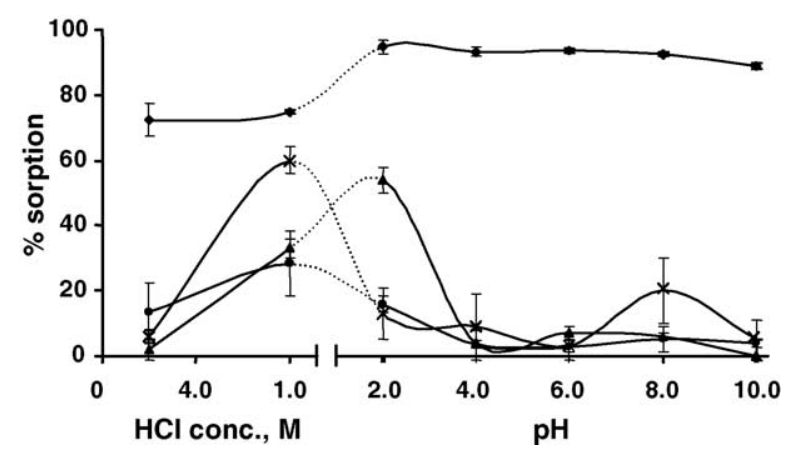

Fig. 4. Percentage uptake of mordenite for $(\bullet) \operatorname{As}(\mathrm{III}),(\times) \operatorname{As}(\mathrm{V}),(\boldsymbol{\vee})$ $\mathrm{Sb}(\mathrm{III})$ and $(\boldsymbol{\Delta}) \mathrm{Sb}(\mathrm{V})$ as a function of $\mathrm{pH}$ and $\mathrm{HCl}$ concentration. (Species concentrations: $\left.40.0 \mu \mathrm{g} \mathrm{l}{ }^{-1}, 1 \%(\mathrm{~m} / \mathrm{v}) \mathrm{NaBH}_{4}, 0.12 \mathrm{M} \mathrm{HCl}\right)$.

whereas percentage uptake values towards $\mathrm{Te}(\mathrm{IV}), \mathrm{Te}(\mathrm{VI})$, $\mathrm{Se}(\mathrm{IV}), \mathrm{Se}(\mathrm{VI}), \mathrm{Sb}(\mathrm{V})$ were $19 \pm 2,4 \pm 1,9 \pm 8,1 \pm 1$, and $2 \pm 2$, respectively. Except $\mathrm{Sb}(\mathrm{III})$, none of the volatile hydride-forming elements investigated had a suppression effect on As(III) signal, under the experimental conditions employed (Fig. 3(b)).

Different sorption behavior of mordenite towards $\mathrm{Sb}(\mathrm{III})$ necessitated a further investigation of the case. For this purpose, effect of solution $\mathrm{pH}$ and $\mathrm{HCl}$ concentration on the sorption of $\mathrm{As}(\mathrm{III}), \mathrm{As}(\mathrm{V}), \mathrm{Sb}(\mathrm{III})$, and $\mathrm{Sb}(\mathrm{V})$ on mordenite were examined more closely. The results are shown in Fig. 4. It can be said that mordenite shows high adsorption selectivity for $\mathrm{Sb}$ (III) at $\mathrm{pH}$ 4.0-6.0. The high selectivity of mordenite for $\mathrm{Sb}$ (III) among the hydride-forming elements investigated may also lead to such applications as separation and preconcentration of $\mathrm{Sb}$ (III) from solutions containing the species with similar chemical properties like As(III).

Another set of experiments was also planned in order to reveal some of physicochemical aspects of $\mathrm{Sb}$ (III) sorption on mordenite as explained in Section 2.4.

\subsubsection{Sorption isotherm and thermodynamic relations in Sb uptake by mordenite}

The sorption experiments of $\mathrm{Sb}$ (III) were performed in the batch process. The equilibrium relationship between the amount of $\mathrm{Sb}$ (III) adsorbed per unit mass of mordenite $\left([C]_{\mathrm{s}}\right)$ and the residual $\mathrm{Sb}(\mathrm{III})$ concentration $\left([C]_{1}\right)$ in solution phase were expressed using adsorption isotherms. The $\mathrm{Sb}$ (III) concentrations ranged from 5.00 to $500 \mathrm{mg}^{-1}$ and two different amounts of solid ( 0.3 and $1 \mathrm{~g}$ ) and temperatures (30 and $50^{\circ} \mathrm{C}$ ) were examined. The applicability of the Freundlich sorption isotherm was tested under these specified conditions.
The general expression of Freundlich isotherm is given as:

$[C]_{\mathrm{s}}=k[C]_{1}^{n}$

where $[C]_{\mathrm{s}}$ is the equilibrium concentration of the sorbed species on the solid phase (meq $\mathrm{g}^{-1}$ ); $[C]_{1}$ the equilibrium concentration of the sorbate in the liquid phase $\left(\right.$ meq $\left.\mathrm{ml}^{-1}\right) ; k$ the constant related to sorption affinity; $n$ the constant related to linearity of the sorption curve.

This expression can be linearized as:

$\log [C]_{\mathrm{s}}=\log k-n \log [C]_{1}$

Thus, plotting $\log [C]_{\mathrm{s}}$ versus $\log [C]_{1}$ would lead to linear behavior with ' $n$ ' being the slope and ' $k$ ' the intercept of the isotherms. Freundlich isotherm model allows for several kinds of adsorption sites on the solid, each kind having a different heat of adsorption. The Freundlich isotherm represents well the data at low and intermediate concentrations and is a good model for heterogeneous surfaces. When the value of Freundlich constant $n$ is equal to unity, Freundlich equation becomes linear and the Freundlich constant $k$ becomes equivalent to the distribution ratio, $R_{\mathrm{d}}$ which is an empirical constant usually used in the quantification of the sorption process [22].

As can be seen from Fig. 5, the adsorption data for $\mathrm{Sb}$ on mordenite follows the Freundlich isotherm. The characteristic Freundlich constants are given in Table 3.

In batch adsorption processes, the adsorption reaction can be written as:

$C_{1}+\underline{s} \Leftrightarrow C_{\mathrm{s}}$

where $C_{1}$ and $C_{\mathrm{s}}$ stands, respectively, for the equilibrium concentration of the sorbate species in the liquid and on the solid sorbent, and $\underline{s}$ refers to the concentration of the sorption sites on the sorbent. The importance of $s$ stems from the fact that sorption sites can act as the limiting reactant when the sorption reaction takes place at higher loadings of the sorbate, the thing that leads to a plateau of saturation beyond a certain high initial concentration. For dilute solutions, the fractional coverage of the sorption sites can be assumed to be small enough to justify approximating the activity (or concentration) of the sorption sites to be constant, and the activity coefficients of the sorbate species in liquid solution and at the solid to be equal to unity. Under these approximations, the equilibrium constant of the above reaction becomes equivalent to the distribution ratio, $R_{\mathrm{d}}\left(\mathrm{ml} \mathrm{g}^{-1}\right)$, an empirical constant that is valid at a certain concentration for a particular set of experimental

Table 3

The calculated Freundlich isotherm constants, $\Delta G^{\circ}, \Delta H^{\circ}$ and $\Delta S^{\circ}$ values from adsorption data

\begin{tabular}{|c|c|c|c|c|c|c|c|c|}
\hline \multirow[t]{2}{*}{$\overline{m / V\left(\mathrm{~g}^{-1}\right)}$} & \multicolumn{2}{|l|}{$n$} & \multicolumn{2}{|c|}{$k\left(\right.$ meq g $\left.^{-1}\right)$} & \multicolumn{2}{|c|}{$\Delta G^{\circ}\left(\mathrm{kJ} \mathrm{mol}^{-1}\right)$} & \multirow[t]{2}{*}{$\Delta H^{\circ}\left(\mathrm{kJ} \mathrm{mol}^{-1}\right)$} & \multirow[t]{2}{*}{$\overline{\Delta S^{\circ}\left(\mathrm{J} \mathrm{mol}^{-1} \mathrm{~K}^{-1}\right)}$} \\
\hline & $303 \mathrm{~K}$ & $323 \mathrm{~K}$ & $303 \mathrm{~K}$ & $323 \mathrm{~K}$ & $303 \mathrm{~K}$ & $323 \mathrm{~K}$ & & \\
\hline 10 & 0.32 & 0.27 & 0.20 & 0.15 & -8.2 & -9.7 & 13.9 & 73.1 \\
\hline 33.3 & 0.19 & 0.27 & 0.04 & 0.11 & -8.8 & -10.4 & 14.3 & 76.3 \\
\hline
\end{tabular}



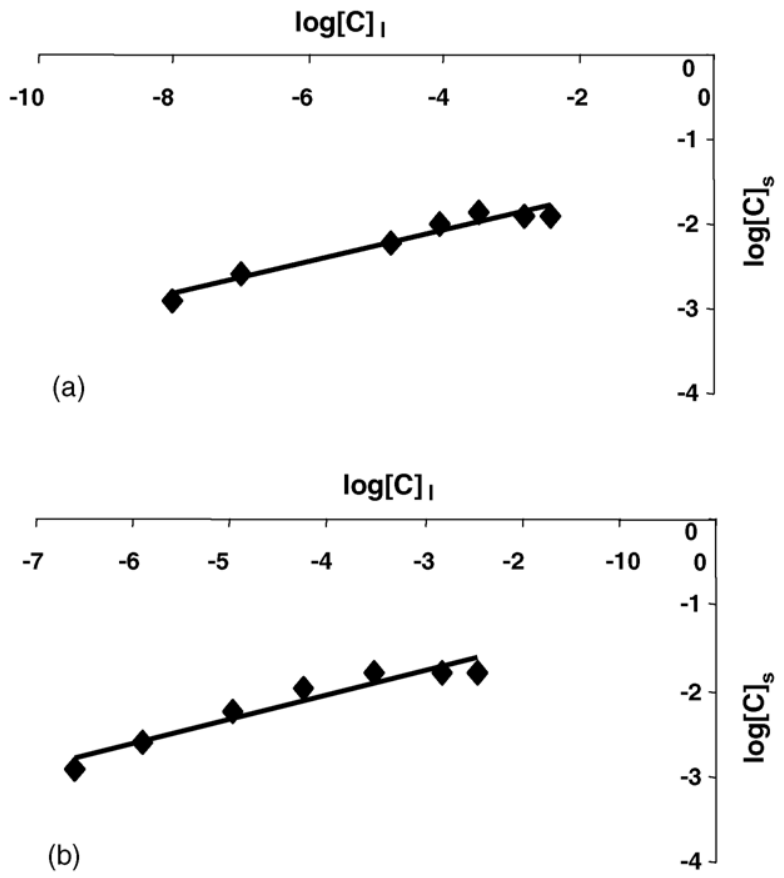

Fig. 5. Freundlich isotherm model curves when plotted for the initial $\mathrm{Sb}(\mathrm{III})$ concentrations of $5.00-500 \mathrm{mg} \mathrm{l}^{-1}$ (amount of mordenite: $1 \mathrm{~g}$ ) (a) at $30^{\circ} \mathrm{C}$ $\left(y=0.1898 x-1.3217, R^{2}=0.951\right)$ and (b) at $50^{\circ} \mathrm{C}(y=0.2742 x-0.9684$, $\left.R^{2}=0.9192\right)$.

conditions, and defined as:

$R_{\mathrm{d}}=\frac{[C]_{\mathrm{S}}}{[C]_{1}}$

under such condition, when the equilibrium is attained, the distribution ratio may be related to the change in Gibbs free energy, $\Delta G^{\circ}$, by the following equation:

$\Delta G^{\circ}=-R T \ln R_{\mathrm{d}}$

Gibbs free energy can also be written in terms of enthalpy change, $\Delta H^{\circ}$, and the entropy change, $\Delta S^{\circ}$, as given below:

$\Delta G^{\circ}=\Delta H^{\circ}-T \Delta S^{\circ}$

Here, $\Delta H^{\circ}$ can be calculated using the relation:

$\Delta H^{\circ}=R \ln \frac{R_{\mathrm{d}}\left(T_{2}\right)}{R_{\mathrm{d}}\left(T_{1}\right)}\left(\frac{1}{T_{1}}-\frac{1}{T_{2}}\right)^{-1}$

As can be seen from Table 3 , the calculated $\Delta G^{\circ}$ values indicate that the sorption process is spontaneous in all cases. It is also obvious that spontaneity increases with increasing temperature leading to higher coverage at higher temperatures. The endothermic nature of sorption of $\mathrm{Sb}$ on mordenite is indicated by the positive values of the enthalpy change $\Delta H^{\circ}$. The positive sign of the $\Delta S^{\circ}$ values indicate that sorption leads to more randomness/mobility in the system, possibly due to the dehydration steps and/or release of a larger number of ions or molecules by mordenite upon fixation of $\mathrm{Sb}$ species.

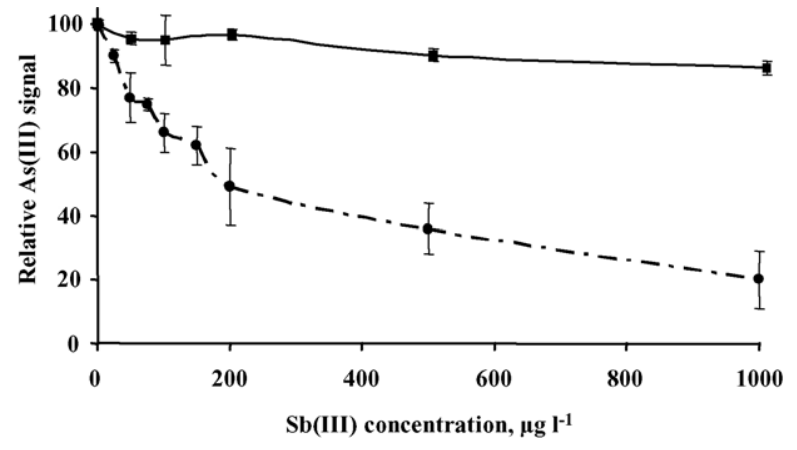

Fig. 6. Effect of $\mathrm{Sb}(\mathrm{III})$ on As(III) signal (O) before and ( $\boldsymbol{\square})$ after the proposed mordenite pretreatment. (As(III) concentration: $40.0 \mu \mathrm{gl}^{-1}$ ).

Meanwhile, the uptake of $\mathrm{Sb}$ (III) species on mordenite was studied using XRD and SEM-EDX techniques. According to the XRD patterns, mordenite reflections were unaffected, in terms of peak positions, intensity, and peak shapes, thus indicating the structural stability of this mineral upon retention of $\mathrm{Sb}$ (III) species, under the experimental conditions employed. Moreover SEM micrographs showed no change in the morphology or crystal size of mordenite particles upon loading with $\mathrm{Sb}(\mathrm{III})$, the signals of which were observed to be equally distributed on the surface of mordenite, as implied by EDX mapping analysis.

\subsubsection{Reduction of $S b$ (III) interference on As(III) signal}

As explained in Section 3.1.2, Se(IV) and Te(IV) did not cause any suppression on As(III) signal under the experimental conditions employed whereas $\mathrm{Sb}$ (III) had a serious suppression effect even at very low concentrations (Fig. 3(b)). Knowing this and the capability of mordenite in sorbing $\mathrm{Sb}(\mathrm{III})$, it was thought that the sample could be pretreated with mordenite which will guarantee the interference-free determination of As(III) in the presence of the above-mentioned volatile hydride-forming elements. This was confirmed as follows; $40.0 \mu \mathrm{g} 1^{-1} \mathrm{As}(\mathrm{III})$ was prepared in varying concentrations of $\mathrm{Sb}(\mathrm{III})$, from 50.0 to $1000.0 \mu \mathrm{g} \mathrm{l}^{-1}$, and the solutions were analyzed both directly and after the proposed mordenite treatment. The results are demonstrated in Fig. 6 . As can be seen from the figure, the presence of $\mathrm{Sb}$ (III) will affect the As(III) signal starting from very low concentrations. But, when the same solutions were processed by mordenite, the As(III) signal is regenerated and the interference of $\mathrm{Sb}$ (III) is reduced to a tolerable level. Even for a solution containing $1000.0 \mu \mathrm{g} 1^{-1} \mathrm{Sb}$ (III), $87 \pm 2 \%$ of the $40.0 \mu \mathrm{g} \mathrm{l^{-1 }}$ As(III) signal is regenerated.

\section{Conclusion}

It has been demonstrated that a pretreatment method utilizing a synthetic zeolite, mordenite, offers an efficient new route for the interference-free determination of As(III) in the presence of $\mathrm{Sb}$ (III) which is one of the most suppressive interferences in As(III) determination by HGAAS. Morden- 
ite exhibits high selectivity towards $\mathrm{Sb}$ (III) and the sorption was observed to be endothermic and followed Freundlich isotherm model. Several other hydride-forming elements, such as $\mathrm{Se}(\mathrm{IV}), \mathrm{Se}(\mathrm{VI}), \mathrm{Te}(\mathrm{IV}), \mathrm{Te}(\mathrm{VI})$ were found not to interfere with As(III) determination with the experimental conditions employed. The proposed pretreatment method was also shown to be capable of reducing the interference effects of several transition metal ions $\left(\mathrm{Ag}^{+}, \mathrm{Ni}^{2+}, \mathrm{Cu}^{2+}\right.$, and $\mathrm{Pb}^{2+}$ ) in the reaction medium.

\section{Acknowledgements}

We would like to acknowledge the İzmir Institute of Technology for support of this work through the fund 2004 IYTE 33, and also the Center for Materials Research for the facilities (XRD and SEM-EDX).

\section{References}

[1] T. Gebel, Chem-Biol. Interact. 107 (1997) 131.

[2] B. Welz, J. Anal. Atom. Spectrom. 13 (1998) 413.

[3] A.K. Das, M. Guardiai, M.L. Cervera, Talanta 55 (2001) 1.
[4] J. Dedina, D.L. Tsalev, Hydride Generation Atomic Absorption Spectrometry, Wiley, Chichester, 1995.

[5] B. Welz, M. Schubert-Jacobs, J. Anal. Atom. Spectrom. 1 (1986) 23.

[6] I.D. Brindle, X.-C. Le, Anal. Chim. Acta 229 (1990) 239.

[7] Y. An, S.N. Willie, R.E. Sturgeon, Spectrochim. Acta B 47 (1992) 1403.

[8] R.C. Campos, P. Grinberg, I. Takase, A.S. Luna, Spectrochim. Acta B 57 (2002) 463.

[9] B. Welz, M. Melcher, Anal. Chim. Acta 131 (1981) 17.

[10] K. Dittrich, R. Mandry, Analyst 111 (1986) 277.

[11] P. Barth, V. Krivan, R. Hausbeck, Anal. Chim. Acta 263 (1992) 111.

[12] Ü. Ay, E. Henden, Spectrochim. Acta B 55 (2000) 951.

[13] N. Erdem, E. Henden, Anal. Chim. Acta 505 (2004) 59.

[14] P. Pohl, W. Zyrnicki, Anal. Chim. Acta 468 (2002) 71.

[15] R. Belcher, S.L. Bogdanski, E. Henden, A. Townshend, Anal. Chim. Acta 113 (1980) 13.

[16] P. Misaelides, A. Godelitsas, S. Kossionidis, G. Manos, Nucl. Instrum. Meth. B 1 (1996) 296.

[17] C. Farm, Sci. Total Environ. 298 (2002) 17.

[18] E. Alvarez-Ayuso, A. Garcia-Sanchez, X. Querol, Water Res. 37 (2003) 4855.

[19] Aslı Erdem, M.Sc. Thesis, IYTE, İzmir, Turkey, 2002.

[20] F. Sahin, M. Volkan, A.G. Howard, O.Y. Ataman, Talanta 60 (2003) 1003.

[21] A. Körez, A.E. Eroğlu, M. Volkan, O.Y. Ataman, J. Anal. Atom. Spectrom. 15 (2000) 1599.

[22] T. Shahwan, H.N. Erten, J. Radioanal. Nucl. Chem. 241 (1999) 151. 